\title{
Masing Behavior and Microstructural Change of Quenched and Tempered High-Strength Steel Under Low Cycle Fatigue
}

\author{
Feng-Mei Bai ${ }^{1,3} \cdot$ Hong-Wei Zhou $^{2} \cdot$ Xiang-Hua Liu $^{1} \cdot$ Meng Song $^{2} \cdot$ Ya-Xin Sun ${ }^{2} \cdot$ Hai-Long Yi $^{1} \cdot$ Zhen-Yi Huang $^{3}$
}

Received: 20 December 2018 / Revised: 1 March 2019 / Published online: 4 April 2019

(C) The Chinese Society for Metals (CSM) and Springer-Verlag GmbH Germany, part of Springer Nature 2019

\begin{abstract}
Low cycle fatigue behavior of a quenched and tempered high-strength steel (Q960E) was studied in the strain amplitude ranging from $\pm 0.5 \%$ to $\pm 1.2 \%$ at room temperature. As a result of fatigue loading, the dislocation structural evolution and fracture mechanism were examined and studied by transmission electron microscopy and scanning electron microscopy (SEM). The results showed that this Q960E steel showed cyclic softening at different strain amplitudes, and the softening tendency was more apparent at strain amplitude of $\pm(0.6-1.2) \%$ than that at $\pm 0.5 \%$. The reduction in dislocation density with increasing strain amplitude is responsible for the softening tendency of cyclic stress with the strain amplitude. The material illustrates near-Masing behavior at strain amplitude ranging from $\pm 0.6 \%$ to $\pm 1.2 \%$. The near-Masing behavior of Q960E high-strength steel can be the result of stability of martensite lath at different strain amplitudes. Partial transformation from martensite laths to dislocation cells is responsible for the derivation from ideal Masing behavior. In the SEM examination of fracture surfaces, transgranular cracks initiate on the sample surface. Striations can be found during the crack propagation stage.
\end{abstract}

Keywords High-strength steel $\cdot$ Low cycle fatigue $\cdot$ Near-Masing behavior $\cdot$ Martensite lath

\section{Introduction}

High-strength steels (HSS) with the yield strength more than $900 \mathrm{MPa}$ have been widely used as a structural material in major equipment, such as coal mining hydraulic support, cement pump truck, large crane boom and mine truck girder. This major equipment in localized regions often undergoes cyclic plastic deformation under service condition. Hence, it is important to consider low cycle fatigue (LCF) behavior

Available online at http://link.springer.com/journal/40195.

Hong-Wei Zhou

zhw.1@ @otmail.com

$\checkmark$ Xiang-Hua Liu

liuxh@mail.neu.edu.cn

1 State Key Laboratory of Rolling and Automation, Northeastern University, Shenyang 110819, China

2 School of Materials Science and Engineering, Anhui Key Lab of Materials Science and Processing, Anhui University of Technology, Maanshan 243002, China

3 School of Metallurgical Engineering, Anhui University of Technology, Maanshan 243002, China in the design of components. LCF behavior of HSS with strength level within 900-1100 MPa has been studied by many researches [1-3]. The results show that steels with high strength have the cyclic softening behavior or cyclic saturation in the cyclic stress response curves. And level of cyclic softening is affected by strain amplitude. At the same time, Masing and non-Masing behaviors of the highstrength steels are related with the cyclic softening-hardening behavior. The modified 9Cr-1Mo steel (P91) under LCF at room temperature (RT) exhibits non-Masing behavior at low strain amplitude of $\pm 0.25 \%$ and Masing behavior at the strain amplitudes $\geq \pm 0.375 \%$ [4]. The $12 \mathrm{Cr}$-ODS (oxidedispersion-strengthened) ferritic steel in the cyclic stress response shows four distinct stages which include instant initial cyclic softening followed by gradual cyclic hardening, continuous linear cyclic softening, and finally fatigue fracture [5]. And the stabilized hysteresis loops in $12 \mathrm{Cr}-$ ODS steel revealed that the Masing behavior occurred at $550{ }^{\circ} \mathrm{C}$, while a progressive deviation from Masing behavior took place at $650{ }^{\circ} \mathrm{C}$. In $34 \mathrm{CrNiMo6}$ high-strength steel, the shape of the hysteresis loops exhibited an ideal Masing behavior [1]. 
Masing and non-Masing behaviors of the high-strength steels may be resulted from different dislocation microstructures. The tempered martensitic structure of P91 steel was unstable and easily transformed into lower energy dislocation cell structure under cyclic loading at room temperature [4]. Otherwise, the tempered martensitic ODS Eurofer steel is stable under cyclic loading at RT and $650-750{ }^{\circ} \mathrm{C}$, and only minor changes in the microstructure are detected [9].

There are different kinds of HSS with different microstructures, for example, quenched and tempered (QT) highstrength steels [6-8], a dual-phase (DP) ferrite-martensite steel $[3,9]$, and ultra-high-strength low-alloy TRIP-aided steels with bainitic-ferrite matrix [6], high-strength bainitic steel $[10,11]$, and quenching and partitioning (Q\&P) steel [12-14]. Among these HSS, 900-1000 MPa grade QT high-strength steels are new type ones, and they have many advantages. Firstly, they have high strength while maintaining good toughness. Secondly, QT high-strength steels are higher than conventional non-tempered low-alloy steels. At the same time, compared with other steels of the same strength, QT high-strength steels have lower content of the carbon and alloy elements. Therefore, they have good weldability, excellent workability, and low cost [14]. A number of studies have focused on LCF of dual-phase (DP) ferrite-martensite steels [3], martensitic steels [15, 16], and high-strength bainitic steels [11]. However, the stability of QT microstructure and fracture mechanism remains unclear under LCF loading. The present work aims at studying LCF behavior and evolution of dislocation structures in a $900 \mathrm{MPa}$ grade high-strength steel (Q960E). The evolution of dislocation structure as a result of fatigue loading is examined by means of TEM. The fatigue crack initiation and propagation, as well as fracture surfaces, are accomplished by SEM examination.

\section{Experimental}

The chemical composition of Q960E steel used in this study is listed in Table 1. The received steel is heat-treated by means of QT process. The QT microstructure of the steel is shown in Fig. 1. The OM image is shown in Fig. 1a. The TEM image in Fig. 1b shows that the steel is composed of martensite laths, and there is higher density dislocation in the interior of martensite laths.

Tensile tests were conducted at RT with a constant strain rate of $3 \times 10^{-4} \mathrm{~s}^{-1}$. The $0.2 \%$ yield strength $\left(\sigma_{0.2}\right)$ is $975 \mathrm{MPa}$ and ultimate tensile strength $\left(\sigma_{\mathrm{UTS}}\right)$ is $1105 \mathrm{MPa}$ for this Q960E steel. The tensile properties of this steel are listed in Table 2.

The samples for fatigue testing are cut from the Q960E plate with the thickness of $6 \mathrm{~mm}$. The schematic diagram of fatigue specimens is shown in Fig. 2. The specimen surface was polished along the longitudinal direction with the emery paper down to \#1000 in order to remove surface defects, such as machining marks and scratches. All LCF tests were carried out under a fully reversed, total axial strain control mode at RT in air. The applied strain amplitude $\left(\Delta \varepsilon_{\mathrm{t}} / 2\right)$ is from $\pm 0.5 \%$ to $\pm 1.2 \%$ controlled by a Shimaduz extensometer at a constant strain rate of $3 \times 10^{-3} \mathrm{~s}^{-1}$, where $\Delta \varepsilon_{\mathrm{t}}$ is the total strain amplitude. A symmetrical triangular waveform was employed using a testing system (Shimaduz IEHFEM200k1-070-0A). Scanning electron microscopy (SEM, JSM-6360LV) was applied to examine the fracture surface of the specimen. Transmission electron microscopy (TEM,

Table 1 Chemical composition of Q960E steel (wt\%)

\begin{tabular}{lllllllll}
\hline $\mathrm{C}$ & $\mathrm{Mn}$ & $\mathrm{Si}$ & $\mathrm{N}$ & $\mathrm{P}$ & $\mathrm{S}$ & $\mathrm{O}$ & $\mathrm{Cr}+\mathrm{Mo}$ & $\mathrm{Nb}+\mathrm{Ti}+\mathrm{V} \mathrm{Fe}$ \\
\hline 0.18 & 1.5 & 0.5 & $\leq 0.004$ & $\leq 0.008$ & $\leq 0.002$ & $\leq 0.0015$ & 1.0 & 0.10 Bal. \\
\hline
\end{tabular}
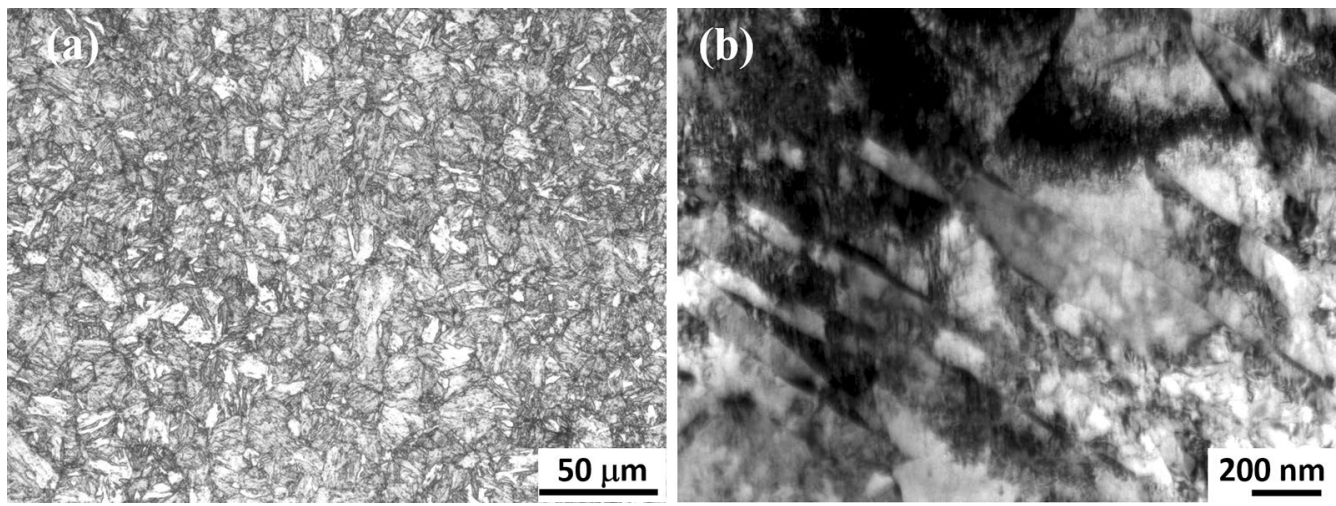

Fig. 1 Microstructure of $900 \mathrm{MPa}$ grade high-strength steel, a OM image, b TEM image 
Table 2 Monotonic tensile properties and parameters of Q960E steel

\begin{tabular}{lllll}
\hline $\begin{array}{l}0.2 \% \text { yield } \\
\text { strength, } \sigma_{0.2}(\mathrm{MPa})\end{array}$ & $\begin{array}{l}\text { Ultimate tensile } \\
\text { strength, } \sigma_{\mathrm{UTS}}(\mathrm{MPa})\end{array}$ & Total elongation, $\delta$ & $\begin{array}{l}\text { Tensile strength coeffi- } \\
\text { cient, } K(\mathrm{MPa})\end{array}$ & $\begin{array}{l}\text { Tensile strain-harden- } \\
\text { ing exponent, } n\end{array}$ \\
\hline 975 & 1105 & $15 \%$ & 660 & 0.16 \\
\hline
\end{tabular}

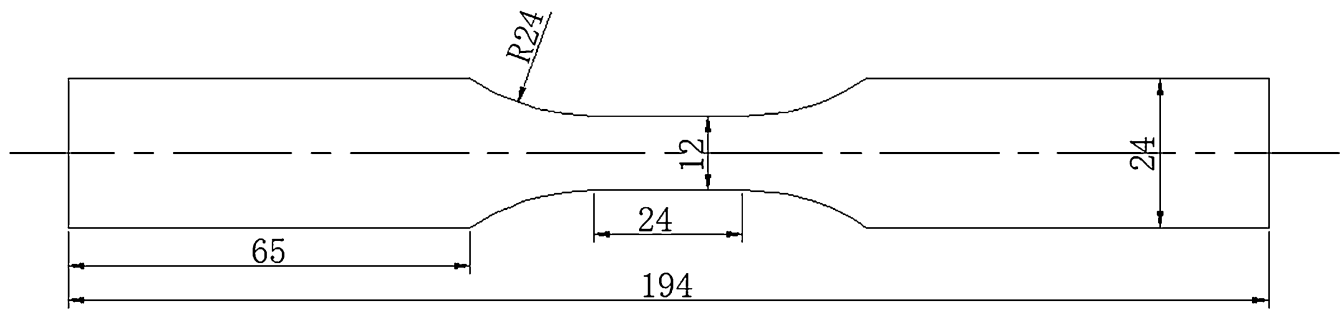

Fig. 2 Specimen geometry used in low cycle fatigue tests

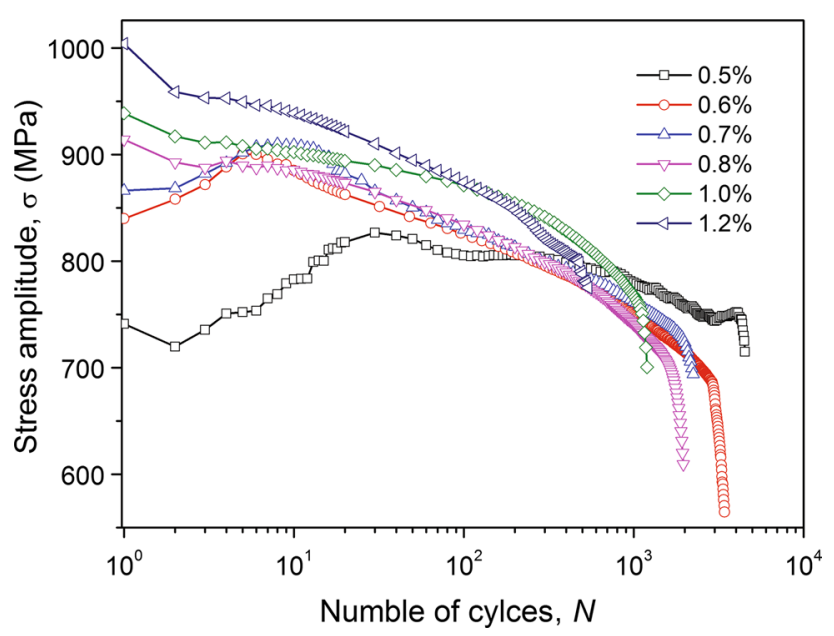

Fig. 3 Cyclic stress response curves of Q960E steel

JEM1200EX) was used to examine the evolution of dislocations under LCF conditions. Samples for TEM are obtained from thin slices cut at $1 \mathrm{~mm}$ away from the fracture surface.

\section{Results and Discussion}

\subsection{Cyclic Stress Response Curves}

The cyclic stress response curves at different stain amplitudes are shown in Fig. 3. As can be seen, the fatigue life reduces with the strain amplitudes. No stabilized state appears at all strain amplitudes. At lower strain amplitudes of $\pm 0.5 \%- \pm 0.7 \%$, it is found that there are two typical stages for cyclic stress response. That is an initial cyclic hardening appeared at the several cycles, followed by cyclic continuous softening with rapid stress drop until fatigue fracture. While, at higher strain amplitudes ranging from $\pm 0.8 \%$ to $\pm 1.2 \%$, all samples illustrate a continuous cyclic softening until a rapid stress drop.

It is worth noting that there are different cyclic stress response curves between below strain amplitude of $\pm 0.6 \%$ and above strain amplitude of $\pm 0.6 \%$, which indicates that the cyclic stress responses rely on the applied strain amplitudes. Cyclic softening is more remarkable at the strain amplitudes from $\pm 0.8 \%$ to $\pm 1.2 \%$ than that at $\pm 0.5 \%$. In particular, the trend of cyclic softening behaviors at the strain amplitudes from $\pm 0.8 \%$ to $\pm 1.2 \%$ shows the same trend. These continuous cyclic softening behaviors are also found in 34CrNiMo6 high-strength steel with strain amplitudes in the range of $\pm 0.4- \pm 2.0 \%$ [1], 9-12\% Cr steels [15-18] and austenitic stainless steel $[19,20]$.

\subsection{Hysteresis Loops and Cyclic Stress-Strain Curve}

To further study the cyclic softening without a stabilized state at the different strain amplitudes, it is necessary to investigate the half-life hysteresis loop. Cyclic stress-strain curve of Q960E steel is originated from the half-life hysteresis loop with the different strain amplitudes, as shown in Fig. 4. Meanwhile, tensile stress-strain curve is also shown in Fig. 4. It can be seen that at lower strain amplitudes of $\pm 0.5 \%$, the area of hysteresis loops is very small, indicating that elastic strain is much higher than plastic strain. Similarly, in 34CrNiMo6 high-strength steel with continuous cyclic soften behaviors, plastic strain is negligible at low strain amplitudes below $\pm 0.5 \%$ [1]. The tensile stress-strain curve lying above cyclic stress-strain curve in Fig. 4 indicates that cyclic softening behavior of Q960E steel under LCF loading. 


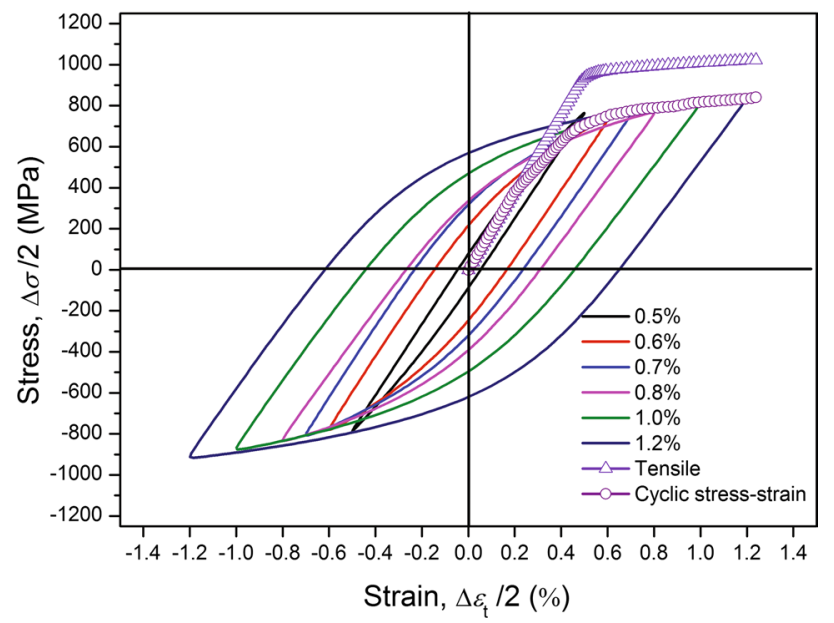

Fig. 4 Comparison between tensile stress-strain curve and cyclic stress-strain curve from Half-life hysteresis loops at a range of total strain amplitude between $\pm 0.5 \%$ and $\pm 1.2 \%$

This result is consistent with that of cyclic stress response in Fig. 3. The cyclic stress-strain curve can be represented by the following power law relationship [5]:

$\Delta \sigma / 2=K^{\prime}\left(\Delta \varepsilon_{\mathrm{p}} / 2\right)^{n^{\prime}}$

where $K^{\prime}$ is the cyclic strength coefficient, $n^{\prime}$ is the cyclic strain-hardening exponent, $\Delta \sigma$ is the amplitude of stress, and $\Delta \varepsilon_{\mathrm{p}}$ is the amplitude of plastic strain. The values of monotonic and cyclic stress-strain curve parameters $(K$, $n, K^{\prime}$ and $n^{\prime}$ ) of Q960E high-strength steel are $1117 \mathrm{MPa}$, $0.0195,1363 \mathrm{MPa}$, and 0.0987 , respectively. $K$ and $n$

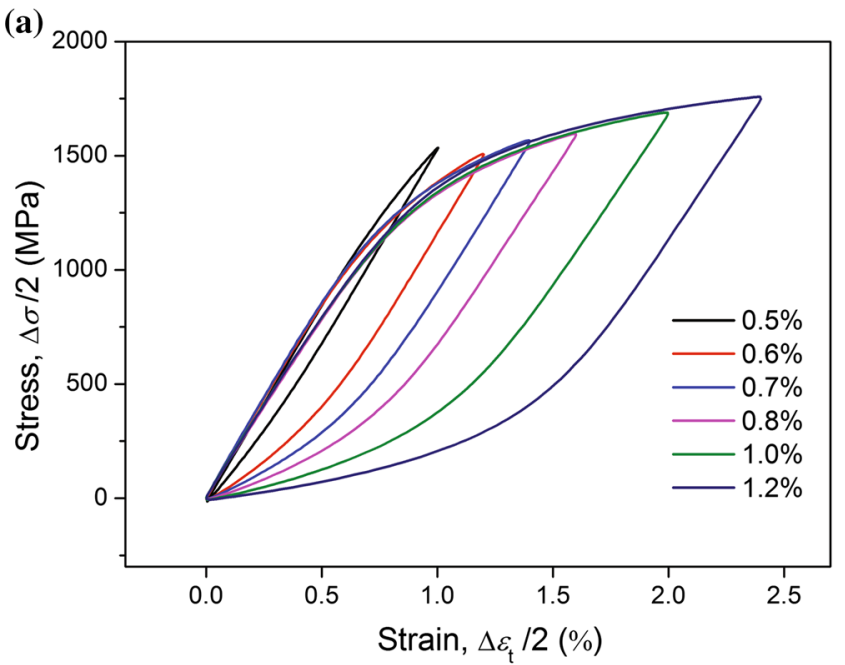

represent tensile strength coefficient and tensile strain-hardening exponent, respectively.

\subsection{Masing and non-Masing Behavior}

The hysteresis loops obtained by LCF test can be used to determine the cyclic stress-strain curve. At the same time, the hysteresis loops can be employed to describe Masing or non-Masing behavior of a material. The plastic strain energy $(\Delta W)$ is associated with the cyclic Masing, or nonMasing behavior of a material. The plastic strain energy is an important parameter to be applied to predict fatigue life under strain-controlled loading. According to the method in Ref. [21, 22], the upper or ascending branches of the stable or half-life hysteresis loops at different strain amplitudes were translated to common origin, as shown in Fig. 5a. It is evident that upper branches of the stable hysteresis loops do not follow the common curve, especially at relatively lower strain amplitudes of $\pm 0.5 \%$, representing the nonMasing behavior. However, at high strain amplitudes of $( \pm 0.6 \%$ to $\pm 1.2 \%)$, the upper parts of stable hysteresis loops are found to almost follow the common loading curve, as shown in Fig. 5a. Sarkar et al. [23] found that plain C-Mn rail steel also deviated from an ideal Masing behavior. However, the divergence was not large enough. Therefore, this behavior in Q960E steel can be defined as near-Masing-type material. In this study, near-Masing behavior is applied to depict Q960E steel under LCF loading at strain amplitude varying from \pm 0.6 to $\pm 1.2 \%$. The stable hysteresis loops in $9 \mathrm{Cr}-1 \mathrm{Mo}$ steel also displayed near-Masing behavior at lower strain amplitudes at RT and $500{ }^{\circ} \mathrm{C}$ [24]. The cyclic stress-strain response of a material may show Masing or

(b)

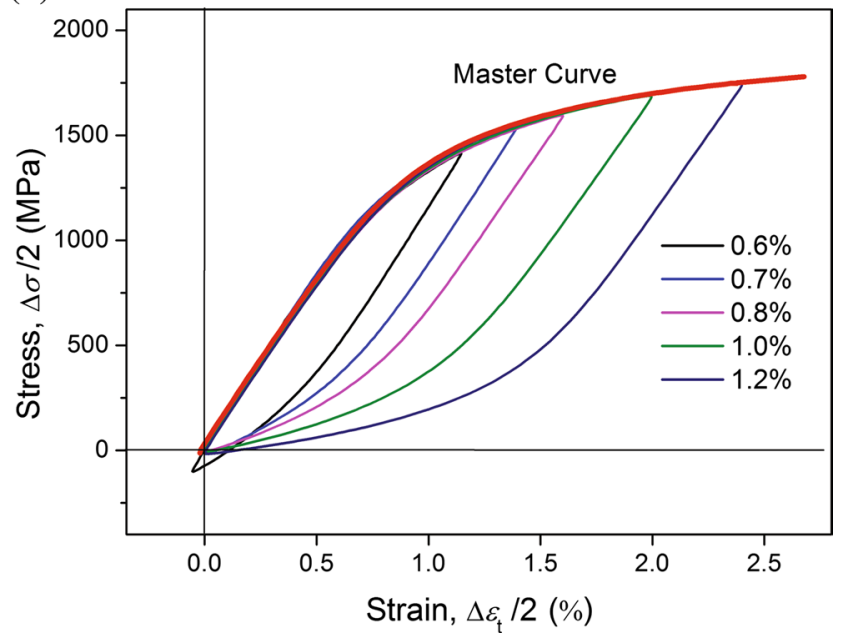

Fig. 5 a Cyclic stress-strain curve obtained by connecting the tips of half-life hysteresis loops; $\mathbf{b}$ construction of master curve obtained by enveloping the upper branches of hysteresis loops 
non-Masing behavior depending on the microstructure and the experimental loading conditions, especially strain amplitude [25].

For non-Masing- and near-Masing-type materials, the master curve can be obtained by enveloping the ascending branches of hysteresis loops at different strain amplitudes $[16,21]$. The master curve for Q960E steel at strain amplitude of $\pm 0.6- \pm 1.2 \%$ is illustrated in Fig. 5b. This master curve is similar to that of the modified $9 \mathrm{Cr}-1 \mathrm{Mo}$ steel under LCF at RT [4]. It is worth noting that this master curve is different from other materials, the ascending branches transfer to left and down direction in Q960E steel, while ascending branches transfer to the opposite directions in other steels, for example, a 304LN austenitic stainless steel and SA333 Gr.6 C-Mn steel [26] and $316 \mathrm{LN}$ stainless steel [25]. The Masing and cyclic hardening-softening behavior of a material is believed to be related with its initial microstructure [15] and loading conditions, such as strain amplitude and temperature. The master curve for Q960E steel being different from other materials $[25,26]$, may be resulted from different microstructures.

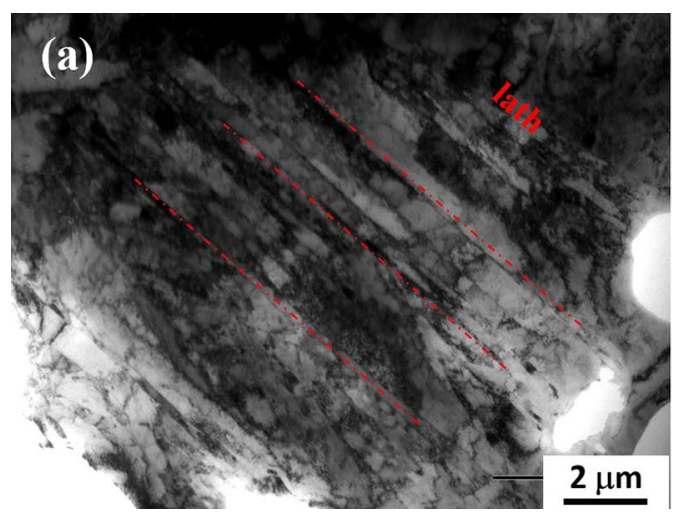

Fig. 6 Martensite lath structures under strain amplitude of $\pm 0.5 \%$
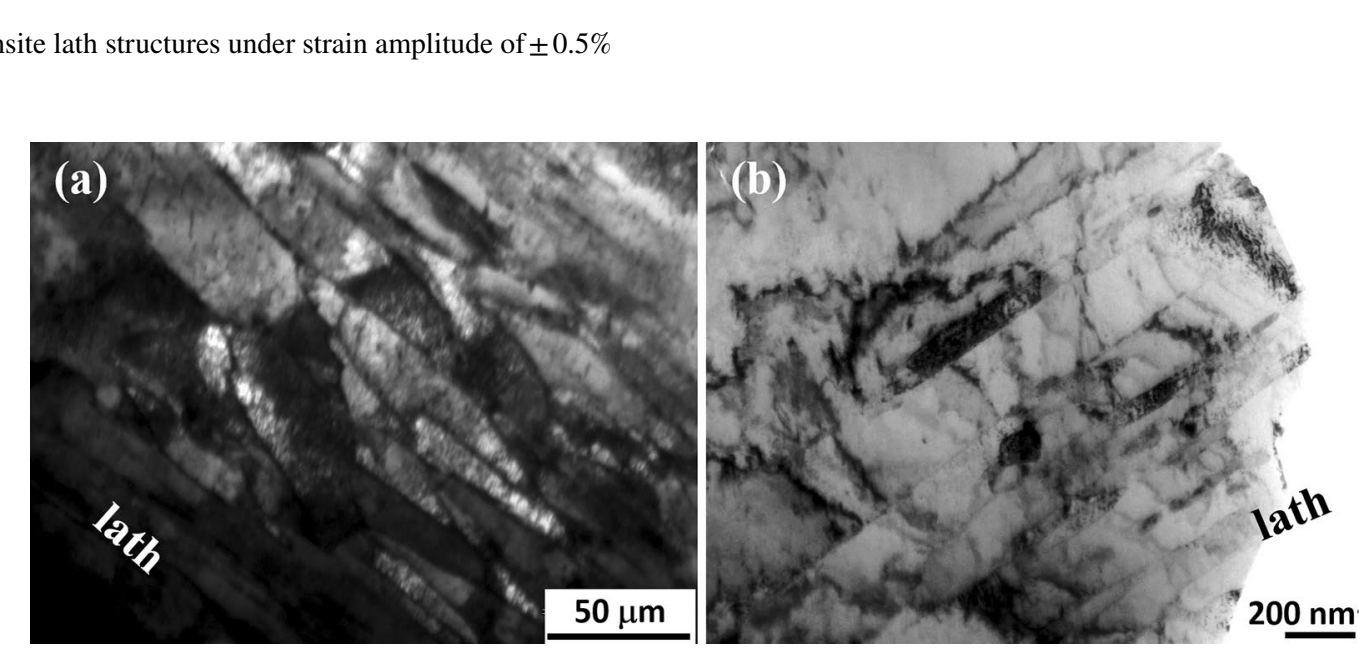

Fig. 7 Martensite lath structures under strain amplitude of $\pm 0.8 \%$

\subsection{Microstructure}

Both cyclic softening at all strain amplitude in Figs. 3 and 4 and near-Masing behavior appear at strain amplitude from $\pm 0.6 \%$ to $\pm 1.2 \%$ in Fig. 5. These mechanical behaviors should be resulted from microstructure evolution under LCF loading. Therefore, microstructure, such as dislocation density and dislocation patterns including martensite laths and cell structures, will be discussed in detail in the following TEM images.

Figures 6, 7, and 8 show the evolution of martensite laths of QT steel investigated by TEM under different strain amplitudes, respectively. At low strain amplitude of $\pm 0.5 \%$, martensite lath is clearly shown in Fig. 6, and dislocation structures are similar to those prior to LCF shown in Fig. 1b. When strain amplitude increases to $\pm 0.8 \%$, martensite lath structures keep stable in Fig. 7, compared with that at low strain amplitude of $\pm 0.5 \%$. At the higher strain amplitude of $\pm 1.2 \%$, martensite lath structures remain largely unchanged in Fig. 8. In Figs. 6 and 7, martensite laths in a prior austenite grain have the same orientation. A clear prior austenite grain boundary (PAGB) is found in Fig. 8, and martensite laths with different orientation arrange on both sides of the PAGB. Note that the

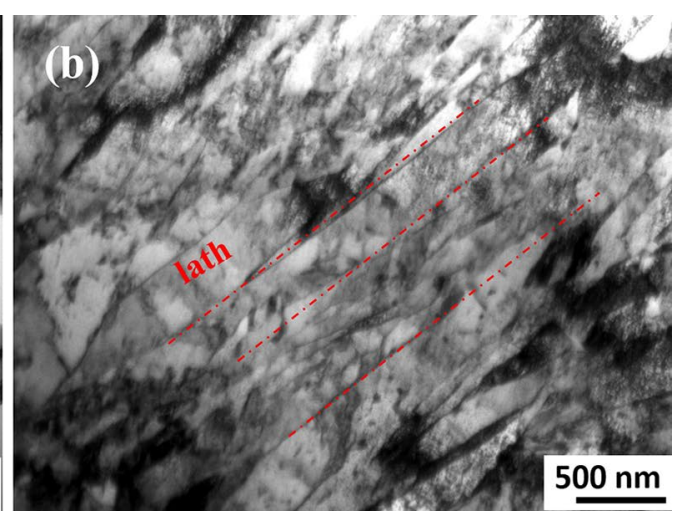




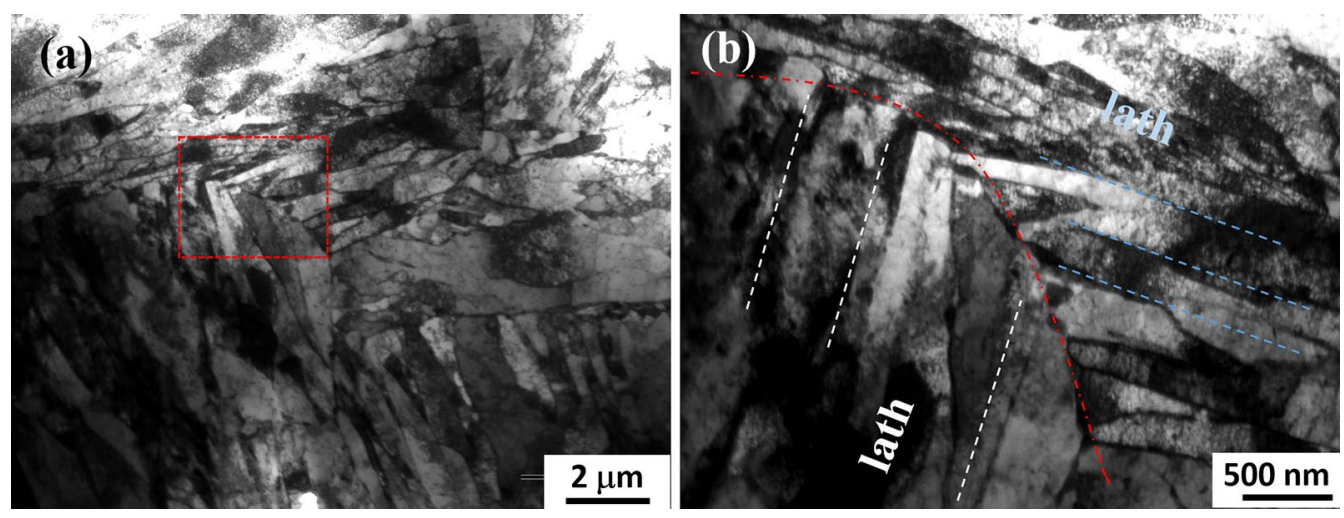

Fig. 8 Martensite lath under strain amplitude of $\pm 1.2 \%, \mathbf{b}$ an enlarged image from the red dotted box in (a)

dislocation density continues to decrease with the increase in strain amplitude varying from $\pm 0.5 \%$ to $\pm 1.2 \%$. The reduction in dislocation density with increasing strain amplitude is responsible for the same softening tendency of cyclic stress with increase in the strain amplitude in Fig. 3. It is worth pointing out that the material nature of Masing behavior is that the deformation structure remains stable under fatigue loading, and is independent of strain amplitude or dislocation motion [25-27]. Therefore, the near-Masing behavior of QT high-strength steel can be due to that the martensite lath hardly changes with the strain amplitude. This result is consistent with that in the 12Cr-ODS ferritic steel. This steel also shows Masing behavior [5]. The microstructure of QT highstrength steel under LCF loading is different from that in P91 martensite steel during mechanical cycling at $550{ }^{\circ} \mathrm{C}$ [16]. The initial lath structure of $\mathrm{P} 91$ steel is entirely transformed into a cell structure. Therefore, P91 steel shows no-Masing behavior.

Figures 9 and 10 show the formation of dislocation cells and reduction in dislocation density at high strain amplitudes. At strain amplitude of $\pm 0.8 \%$, some dislocation cells are produced, and martensite laths are also found near cells. It is clear that dislocation density inside cells and laths is lower than that before LCF loading in Fig. $1 \mathrm{~b}$ and at low strain amplitude of $\pm 0.5 \%$ in Fig. 6 . A lot of nanoscale particles are found inside laths, which are labeled by red arrow in Fig. 9. PAGB is also observed in Fig. 9b. It should be pointed out that these nanoscale particles precipitate in the process of QT treatment rather than under LCF loading. These particles are not easily observed in raw Q960E steel because high-density dislocations shield them. When the steel undergoes high-strain-amplitude LCF, dislocation density decreases inside laths and thus nanoparticles appear. Both high-density dislocations and these nanoparticles are responsible for high strength of Q960E, as shown in Table 1. On the other hand, some dislocation cells form under LCF loading. However, the quantity of dislocation cells is much lower than that of martensite laths. Most martensite laths are very stable, which is helpful for the appearance of Masing behavior in Q960E steel. Some transformation from martensite laths to dislocation cells make the material deviate from the ideal Masing behavior. Hence, near-Masing behavior is investigated in Fig. 5. Based on the detailed observation and discussions of TEM images in Figs. 6, 7, 8, 9, 10, schematic representation of evolution of dislocation structures at low and high strain amplitudes is shown in Fig. 11.
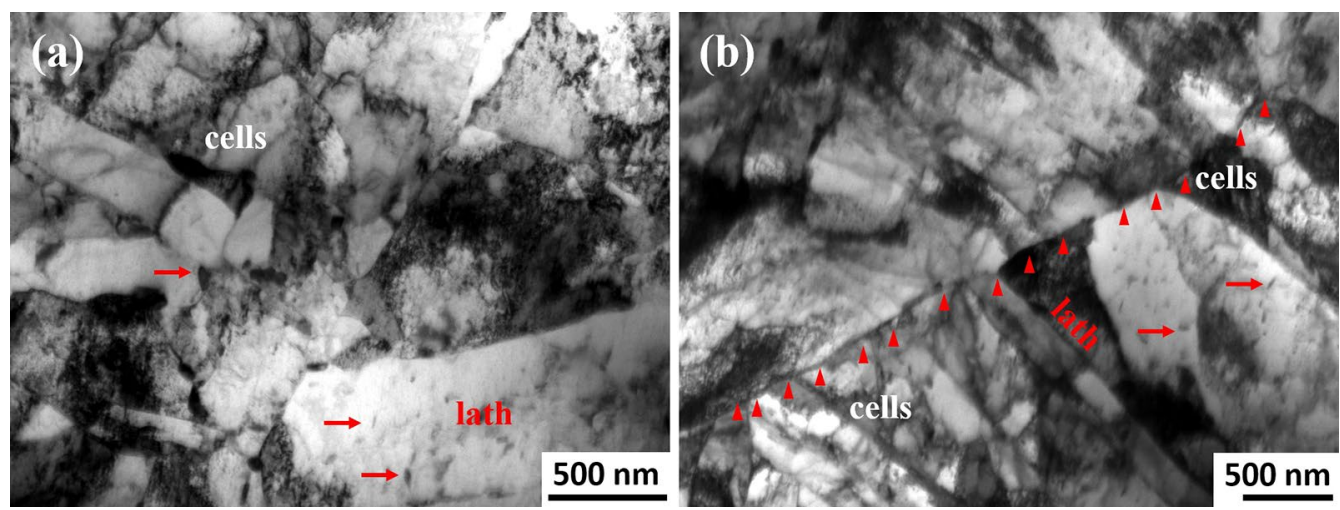

Fig. 9 Martensite lath and dislocation cell structures under strain amplitude of $\pm 0.8 \%$ 

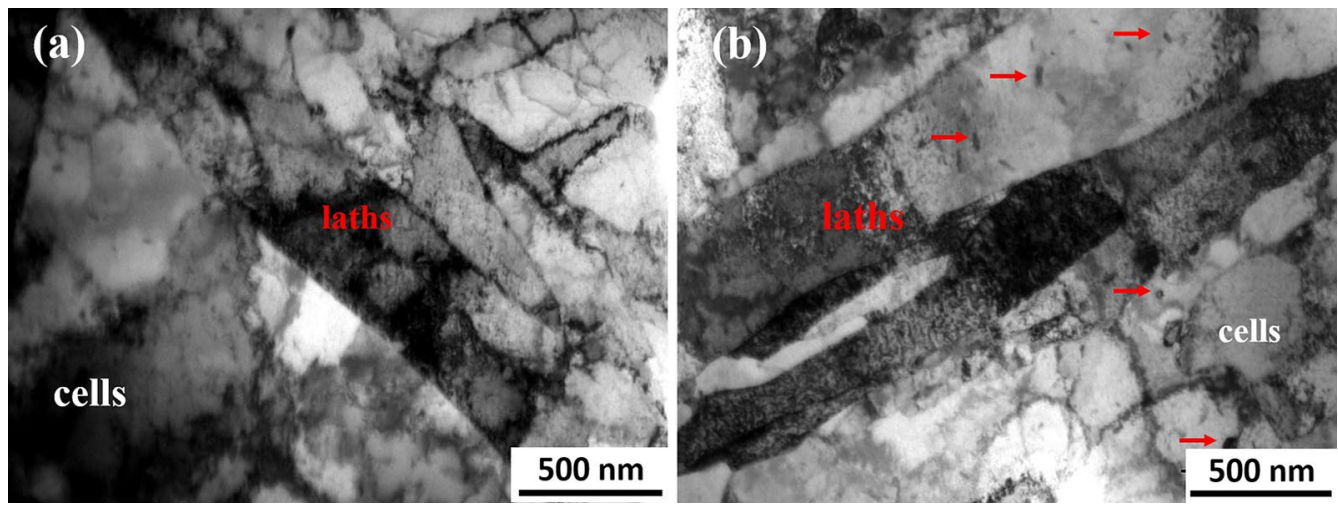

Fig. 10 Martensite lath and dislocation cell structures under strain amplitude of $\pm 1.2 \%$

\subsection{Crack Propagation and Fracture Features}

The crack specimen surface and fracture surfaces are investigated in order to understand the LCF damage of highstrength steel. Figure 12 shows OM micrographs of crack propagation surface of the specimen tested under strain amplitude of $\pm 0.8 \%$. The surface transgranular crack initiates at the surface slip. The fatigue crack formation is predominantly orientated about $45^{\circ}$ to the loading direction (LD), which is commonly called stage I. Stage II
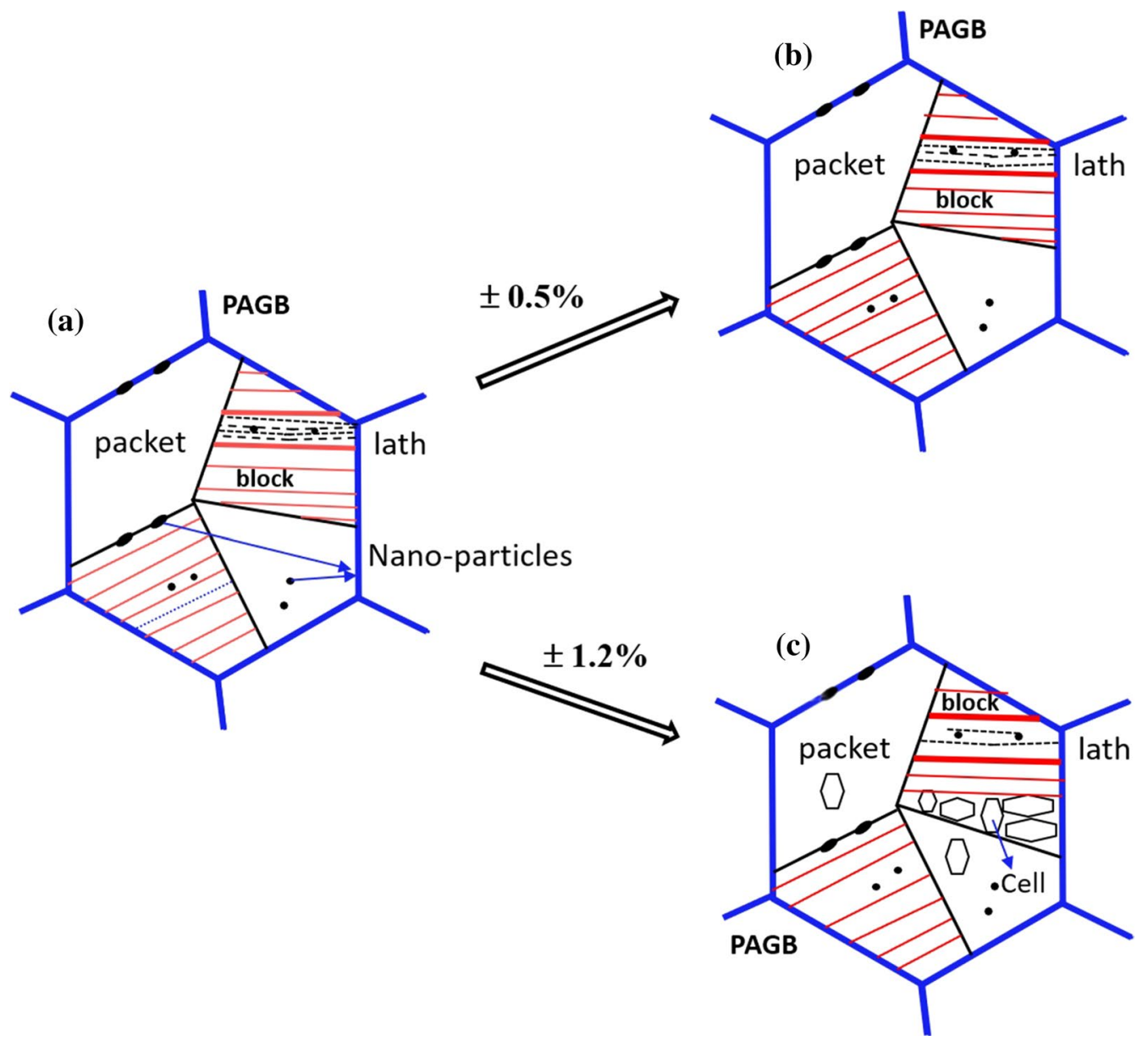

Fig. 11 Schematic representation of evolution of dislocation structures under LCF loading in high-strength steel. PAGB is an abbreviation of prior austenite grain boundary 


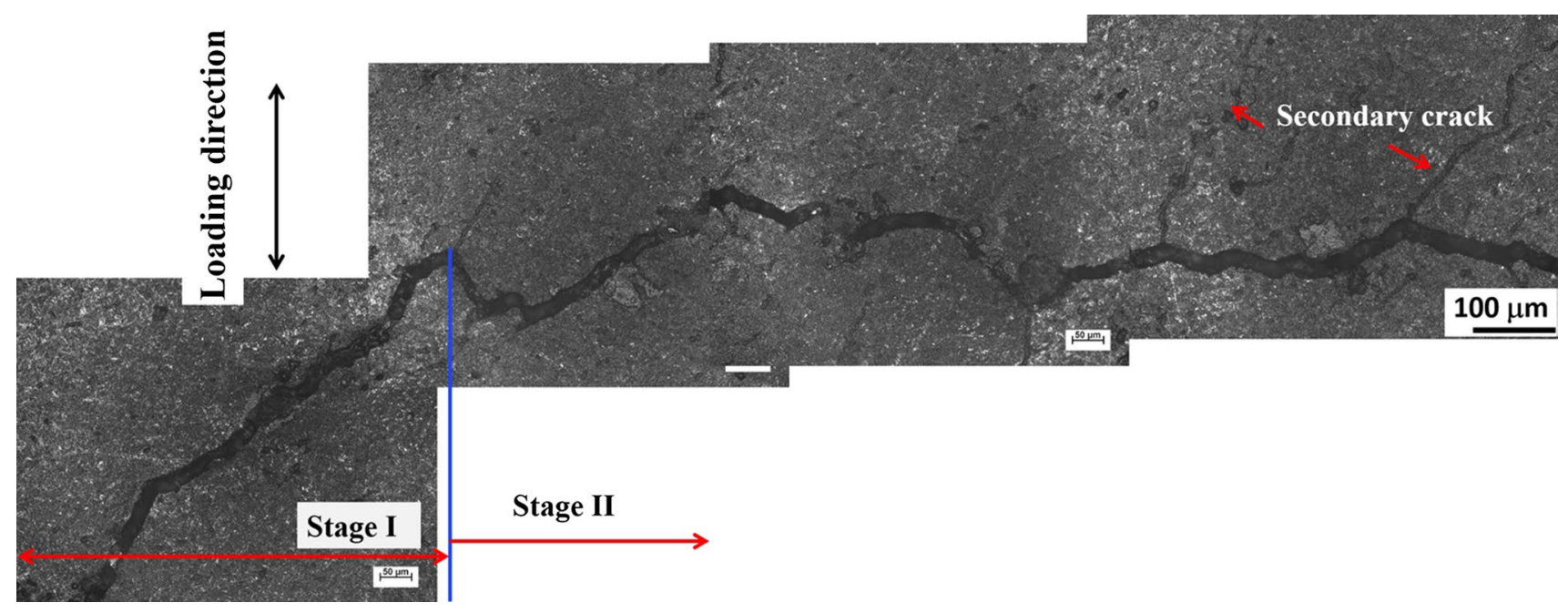

Fig. 12 OM micrographs taken from the surface of the specimen tested under the strain amplitude of $\pm 0.8 \%$

means fatigue crack propagates after stage I crack initiation. Although the crack propagation direction frequently changes, the whole crack direction is almost perpendicular to the LD. The remarkable secondary cracks are observed in stage II (marked red arrows in Fig. 12). These crack orientation relationship to the LD and secondary crack or crack branching are also found in a bimodal $12 \mathrm{Cr}$-ODS steel under high-temperature cyclic loading [5].

Figure 13 shows fracture features of the specimen at $\Delta \varepsilon_{\mathrm{t}}= \pm 0.8 \%$. It can be seen in Fig. 13a that fatigue cracks initiate at the slip bands connected to the specimen free surface instead of the interior of the specimen, designated as
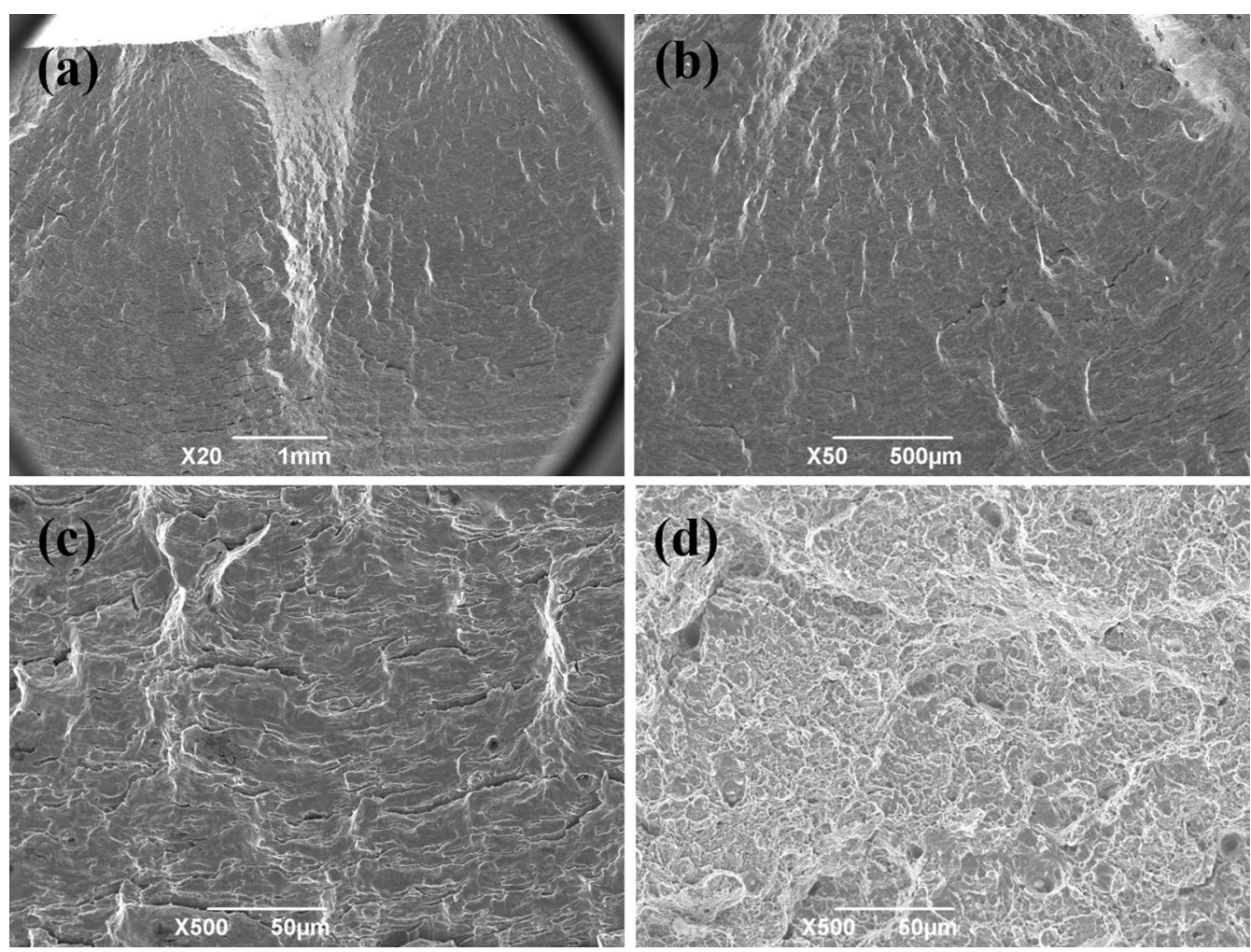

Fig. 13 Fracture features of Q960E steel at $\Delta \varepsilon_{\mathrm{t}}= \pm 0.8 \%$, a crack initiation, $\mathbf{b}$ crack propagation, $\mathbf{c}$ striations, $\mathbf{c}$ an enlarged image from the red box in $\mathbf{b}, \mathbf{d}$ dimple fracture 
stage I in Fig. 13a. Fatigue crack grows from surface into the interior of the specimen, and formation of secondary cracks is shown in Fig. 13b and c. Striations are shown in Fig. 13c. Crack propagation designated as Stage II is transgranular under the LCF conditions, evidenced by striations on the fracture surface. The sudden fracture region of stage III exhibits ductile fracture, as shown in Fig. 13d. In the SEM examination of fracture surfaces, cleavage facets are not found at different stain amplitudes.

\section{Conclusions}

1. Q960E high-strength steel shows cyclic softening behavior at different strain amplitude. It is found that there are two typical stages for low stain amplitudes at $\Delta \varepsilon_{\mathrm{t}} / 2= \pm 0.5 \%- \pm 0.7 \%$, an initial cyclic hardening appeared at the several cycles, followed by cyclic continuous softening with rapid stress drop until fatigue fracture due to crack initiation and growth. At high strain amplitudes ranges from $\pm 0.8 \%$ to $\pm 1.2 \%$, all samples illustrate a continuous cyclic softening until a rapid stress drop. The softening tendency is more apparent at strain amplitude more than $\pm 0.5 \%$.

2. Cyclic softening behavior of Q960E steel is as a result of the reduction of dislocation density under fatigue loading. The dislocation density reduces with increasing strain amplitude. This is responsible for the same softening tendency of cyclic stress with the strain amplitude.

3. The material illustrates near-Masing behavior at strain amplitude ranging from $\pm 0.6 \%$ to $\pm 1.2 \%$. Stable lath structure is responsible for near-Masing behavior of quenched and tempered high-strength steel. The nearMasing behavior can be resulted from the stability of martensite lath at different strain amplitude. Partial transformation from martensite laths to dislocation cells is responsible for derivation from ideal Masing behavior.

4. The Q960E high-strength steel exhibits a characteristic of ductile and transgranular fracture. The surface transgranular crack initiates at the surface slip. The fatigue crack formation is predominantly orientated about $45^{\circ}$ to the loading direction. Stage II means fatigue crack propagates after stage I crack initiation. Striations can be found during crack propagation Stage II. In the SEM examination of fracture surfaces, cleavage facets are not found at different stain amplitudes.
Acknowledgements The authors thank the financial supports of the National Natural Science Foundation of China (No. 51674079) and Anhui Provincial Natural Science Foundation (Nos. KJ2018A0062, KJ2017A128 and KJ2017A066).

\section{References}

[1] R. Branco, J.D. Costa, F.V. Antunes, Theor. Appl. Fract. Mec. 58(1), 28 (2012)

[2] S. Glodež, M. Knez, N. Jezernik, J. Kramberger, Eng. Fail. Anal. 16(7), 2348 (2009)

[3] P.C. Chakraborti, M.K. Mitra, Int. J. Fatigue 28(3), 194 (2006)

[4] P. Verma, N.C.S. Srinivas, S.R. Singh, V. Singh, Mater. Sci. Eng., A 652, 30 (2016)

[5] A. Chauhan, D. Litvinov, J. Aktaa, Int. J. Fatigue 93, Part 1,1 (2016)

[6] R.K. Dutta, M. Amirthalingam, M.J.M. Hermans, I.M. Richardson, Mater. Sci. Eng., A 559, 86 (2013)

[7] W.S. Chang, J. Mater. Sci. 37(10), 1973 (2002)

[8] B. Jiang, M. Wu, M. Zhang, F. Zhao, Z. Zhao, Y. Liu, Mater. Sci. Eng., A 707, 306 (2017)

[9] J.C. Zhang, H.S. Di, Y.G. Deng, S.C. Li, R.D.K. Misra, Mater. Sci. Eng., A 645, 232 (2015)

[10] M.C. Marinelli, I. Alvarez-Armas, U. Krupp, Mater. Sci. Eng., A 684, 254 (2017)

[11] J. Kang, F.C. Zhang, X.Y. Long, B. Lv, Mater. Sci. Eng., A 666, $88(2016)$

[12] Y.J. Li, D. Liu, W.N. Zhang, J. Kang, D. Chen, G. Yuan, G.D. Wang, Mater. Lett. 230, 36 (2018)

[13] F. Peng, Y. Xu, X. Gu, Y. Wang, X. Liu, J. Li, Mater. Sci. Eng., A 723, 247 (2018)

[14] X.U. Zhenlin, J. Fang, Hot Working Technology 45(15), 4 (2017)

[15] B. Fournier, M. Sauzay, A. Rarcelo, F. Barcelo, A. Pineau, J. Nucl. Mater. 71, 386-388 (2009)

[16] H.W. Zhou, Y.Z. He, H. Zhang, Y.W. Cen, Int. J. Fatigue 47, 83 (2013)

[17] B. Fournier, M. Sauzay, C. Caës, M. Noblecourt, M. Mottot, A. Bougault, V. Rabeau, A. Pineau, Int. J. Fatigue 30(4), 649 (2008)

[18] S.L. Mannan, M. Valsan, Int. J. Mech. Sci. 48(2), 160 (2006)

[19] H.W. Zhou, Y.Z. He, M. Cui, Y.W. Cen, J.Q. Jiang, Int. J. Fatigue 56, 1 (2013)

[20] H.W. Zhou, Y.Z. He, Y.W. Cen, J.Q. Jiang, Adv. Mater. Res. 815, $875(2013)$

[21] F. Ellyin, Fatigue damage, crack growth and life prediction (Springer, Netherlands, 1997), pp. 278-380

[22] D. Lefebvre, F. Ellyin, Int. J. Fatigue 6(1), 9 (1984)

[23] P.P. Sarkar, P.S. De, S.K. Dhua, P.C. Chakraborti, Mater. Sci. Eng., A 707, 125 (2017)

[24] K. Guguloth, S. Sivaprasad, D. Chakrabarti, S. Tarafder, Mater Sci. Eng., A 604, 196 (2014)

[25] S. Goyal, S. Mandal, P. Parameswaran, R. Sandhya, C.N. Athreya, K. Laha, Mater. Sci. Eng., A 696, 407 (2017)

[26] S. Sivaprasad, S.K. Paul, A. Das, N. Narasaiah, S. Tarafder, Mater. Sci. Eng., A 527(26), 6858 (2010)

[27] A. Plumtree, H.A. Abdel-Raouf, Int. J. Fatigue 23(9), 799 (2001) 